Thaís Torres PIRES ${ }^{1}$

Gonzalo ROSTAN ${ }^{1}$

José Eugênio GUIMARÃES²

Correspondência para:

THAÍS PIRES

Cx. Postal 2219

Rio Vermelho

0223-970 - Salvador - BA

thais.vet@tamar.org.br

Recebido para publicação: 18/06/2004 Aprovado para publicação: 01/06/2005

\title{
Hemograma e determinação da proteína plasmática total de tartarugas marinhas da espécie Caretta caretta (Linnaeus, 1758), criadas em cativeiro, Praia do Forte, Município de Mata de São João - Bahia
}

\author{
1 - Instituto Brasileiro do Meio Ambiente e dos Recursos Naturais \\ Renováveis, Mata de São João - BA \\ 2- Departamento de Patologia e Clínicas do Hospital de Medicina Veterinária \\ da Escola de Medicina Veterinária da Universidade Federal da Bahia, \\ Salvador - BA
}

\begin{abstract}
Resumo
Com objetivo de obter valores dos parâmetros do hemograma e de proteína plasmática total, de tartarugas marinhas da espécie Caretta caretta criadas em cativeiro, foram coletados cinco mililitros de sangue através de venopunção do seio venoso cervical dorsal de oito animais daquela espécie, utilizando como anticoagulante a heparina de sódio. Os achados hematológicos mostraram valores médios de eritrócitos de $275.000 / \mu \mathrm{l}( \pm 28.030,59)$, volume globular de 33,12\% ( $\pm 2,35)$, concentração de hemoglobina de $8,65 \mathrm{~g} / \mathrm{dl}( \pm 0,80)$, enquanto que os índices hematimétricos encontrados foram de $725 \mathrm{fl}( \pm 131,99)$ para volume globular médio (VGM), 198,18 pg ( \pm 38,66) para hemoglobina globular média (HGM) e de $26,10 \%( \pm 1,21)$ para concentração de hemoglobina globular média (CHGM). No leucograma a média do número total de leucócitos foi de 3.656/ $\mu \mathrm{l}$ $( \pm 963,04)$, e os valores médios relativos da contagem diferencial de leucócitos foram de 59,38\% ( \pm 16.27$)$ para heterófilos, $10,38 \%( \pm 6,32)$ para eosinófilos, $0,13 \%( \pm 0.35)$ para basófilos, $29,25 \%( \pm 17,12)$ para linfócitos e 0,88\% $( \pm 2,10)$ para monócitos, sendo os valores absolutos de $2.156,87 / \mu \mathrm{l}( \pm 703,49) ; 366,88 / \mu \mathrm{l}( \pm 216,44) ; 2,50 / \mu \mathrm{l}( \pm 7,07)$; $1.110,94 / \mu \mathrm{l}( \pm 783,61)$ e $19,06 / \mu \mathrm{l}( \pm 42,34)$, respectivamente. O valor médio de trombócitos encontrado foi igual a 10.968,13/ $\mu \mathrm{l}( \pm 3.109,19)$ e a determinação de proteína total teve uma média de $6,5 \mathrm{~g} / \mathrm{dl}( \pm 0,83)$. Das variáveis analisadas, a contagem de eritrócitos, o volume globular médio, a hemoglobina globular média e as contagens total e diferencial de leucócitos apresentaram valores diferentes para a espécie em questão, quando comparadas com a literatura consultada.
\end{abstract}

\section{Introdução}

A avaliação hematológica é de grande valor na investigação de doenças em répteis, e pode mostrar alterações fisiológicas entre animais de vida livre e aqueles criados em cativeiro ${ }^{1}$. Contudo, são poucas as informações de valores sangüíneos para as tartarugas marinhas sendo que a maior parte dos estudos apresenta um número reduzido de parâmetros bioquímicos, baseados em
Palavras-chave: Hemograma. Proteína plasmática total. Tartaruga marinha. Caretta caretta. uma pequena quantidade de amostras de animais em cativeiro ou de histórico desconhecido ${ }^{2}$.

Fatores como idade, tamanho, sexo, estação do ano, saúde, habitat e dieta podem afetar os parâmetros hematológicos, tanto em tartarugas marinhas como em répteis de maneira geral, dificultando o estabelecimento de valores sangüíneos de referência e comparações entre indivíduos e populações ${ }^{3,4,5}$. Embora a literatura apresente alguns trabalhos 
publicados sobre valores hematológicos para estes animais, é difícil o uso dessas informações em estudos comparativos, devido às diferenças entre os métodos de coleta, manipulação e processamento das amostras e métodos empregados na análise bioquímica ${ }^{6}$. Além disso, as descrições das características morfológicas de células sangüíneas de quelônios marinhos são limitadas?.

Com a necessidade crescente de avaliação do estado de saúde em tartarugas marinhas, para ser possível a manutenção de animais saudáveis em cativeiro e para reabilitação de indivíduos de vida livre, se faz necessário um maior empenho em desenvolver estudos relacionados aos meios de diagnósticos, onde a avaliação hematológica possui grande destaque.

O presente trabalho propõe a realização do hemograma e determinação da proteína plasmática total em tartarugas marinhas da espécie Caretta caretta criadas em cativeiro, obtendo-se assim valores médios dos constituintes que compõem o eritrograma, leucograma, assim como de trombócitos e proteína plasmática total, de maneira que possam posteriormente ser utilizados como dados auxiliares para o diagnóstico clínico desses animais. Ressaltase aqui a importância dos valores hematológicos no tratamento de animais de vida livre, pois por se tratar de uma espécie vulnerável à extinção, a reintrodução na natureza de indivíduos comprovadamente saudáveis, através dessa avaliação, é de grande valor para os projetos de conservação. Portanto, torna-se imprescindível a realização de pesquisas que visem a determinação de valores hematológicos considerados normais para essa espécie no Brasil, especificamente na Bahia.

\section{Materiais e Métodos}

Foram estudadas amostras de oito tartarugas marinhas da espécie Caretta caretta, clinicamente saudáveis, provenientes do Projeto TAMAR-Ibama, Centro de visitantes da base de Praia do Forte, Município de Mata de São João - Bahia, sendo sete fêmeas e um macho, mantidos em cativeiro desde o nascimento. A média de peso dos animais foi de $114,4 \mathrm{Kg}$, sendo o valor máximo encontrado de $152 \mathrm{Kg}$ e mínimo de $82 \mathrm{Kg}$. O comprimento curvilíneo de carapaça médio foi de $93,6 \mathrm{~cm}$, com valores máximo e mínimo de 102,5 e 83,5 cm respectivamente, enquanto que a idade variou entre 12 e 16 anos.

Cinco ml de sangue de cada animal foram coletados no Seio Venoso Cervical Dorsal, sendo a contenção dos animais realizada de acordo com as recomendações de Owens e Ruiz'.

As amostras foram acondicionadas em tubos de ensaio contendo heparina de sódio, que é o anticoagulante de escolha para as avaliações hematológicas em quelônios ${ }^{6,9,10}$. O material biológico colhido foi enviado e processado no Laboratório de Patologia Clínica do Hospital de Medicina Veterinária da Escola de Medicina Veterinária da UFBA. O volume globular foi determinado por microcentrifugação em tubo capilar em tubos microcapilares, segundo a técnica descrita por Jain ${ }^{11}$. Os valores de concentração de hemoglobina foram obtidos pelo método de cianometahemoglobina, utilizando kit comercial DOLES, segundo as recomendações do fabricante. As contagens de eritrócitos e leucócitos foram realizadas manualmente em Câmara de Neubauer tendo como diluente a solução de Natt e Herrick ${ }^{12}$. A contagem diferencial de leucócitos e a determinação do número de trombócitos foram estabelecidas em esfregaços sangüíneos confeccionados no momento da colheita das amostras e corados pelo método panótico rápido tipo Rosenfeld ${ }^{13}$. O número de trombócitos foi determinado a partir da contagem deste tipo celular em cada 1000 eritrócitos contados. A determinação da proteína plasmática total foi realizada por refratometria. A partir das variáveis do eritrograma estabeleceu-se matematicamente os índices hematimétricos: Volume Globular Médio (VGM), Hemoglobina Globular Média (HGM) eConcentração de Hemoglobina Globular Média (CHGM), expressos em fentolitros (fl), picogramas (pg) e porcentagem (\%), respectivamente.

Foram calculadas médias, desvio 
Tabela 1 - Média, desvio padrão, valor máximo, valor mínimo, mediana dos valores hematológicos e de proteína plasmática total de tartarugas marinhas da espécie Caretta caretta $(n=8)$, criadas em cativeiro, Salvador - BA. 2003

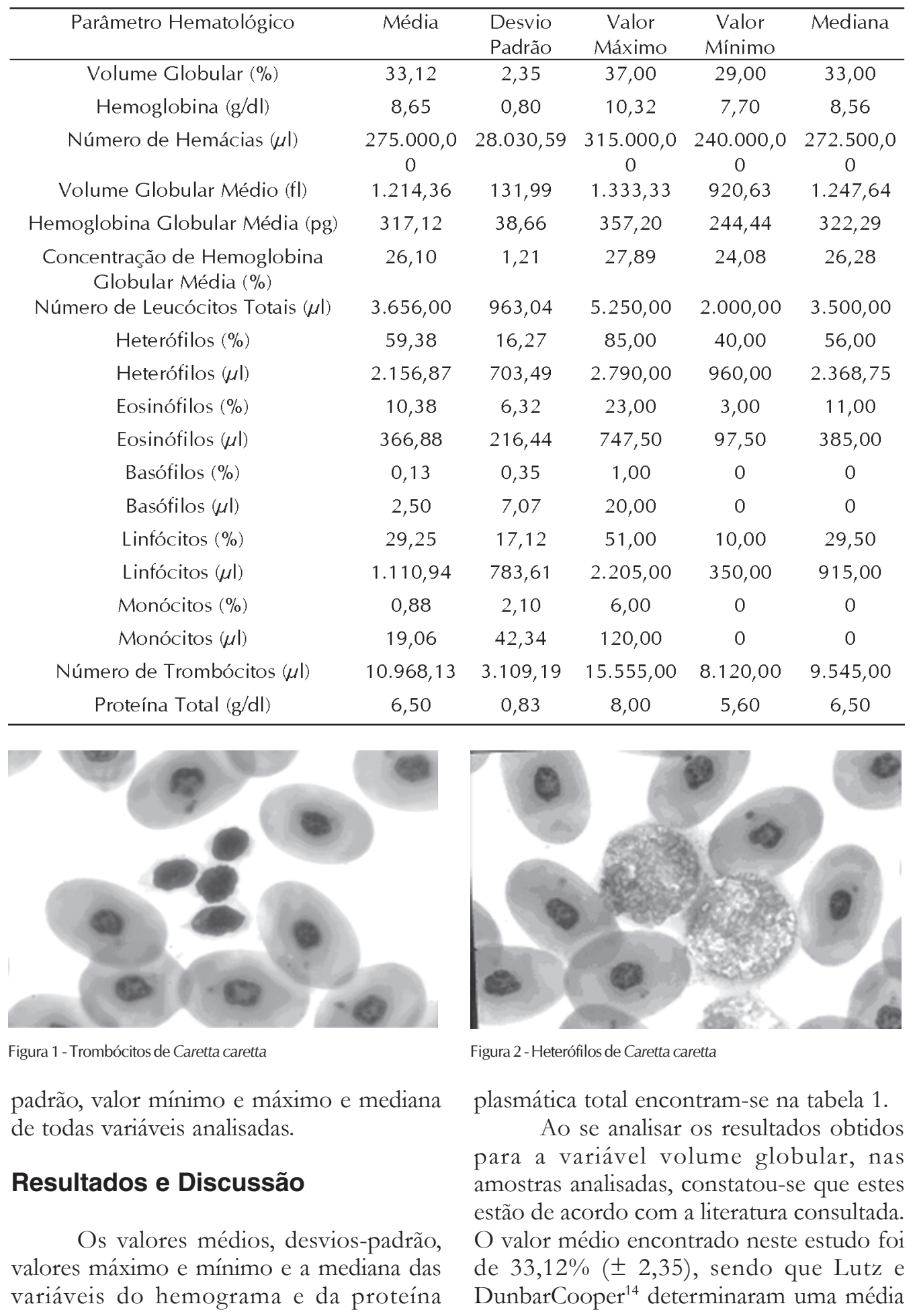




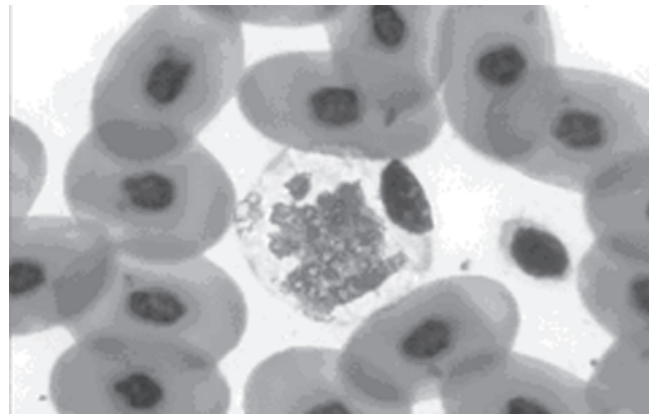

Figura 3 - Eosinófilo de Caretta caretta

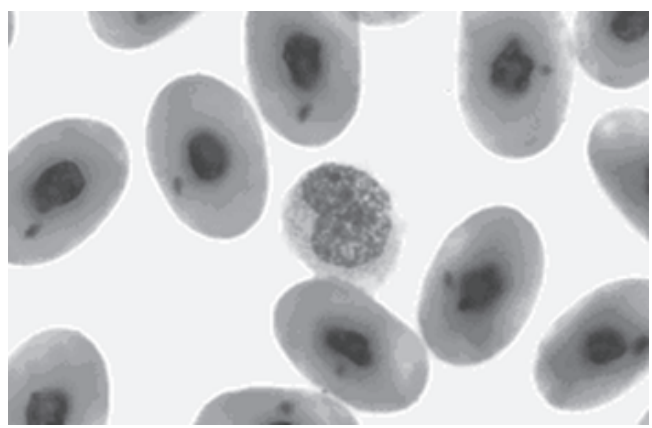

Figura 5-Monócito de Caretta caretta

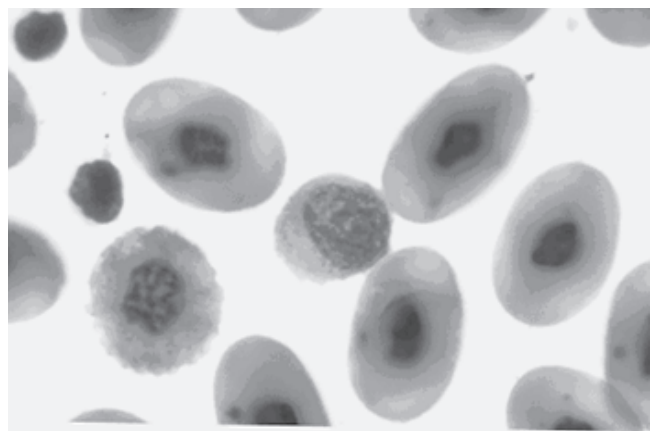

Figura 4 - Linfócito de Caretta caretta

de $35,4 \%$, para animais de vida livre desta mesma espécie. Já, para a tartaruga verde (Chelonia mydas), Bolten e Bjorndal ${ }^{2}$ e Aguirre et al. ${ }^{15}$ obtiveram valores de $35,2 \%$ e $31,2 \%$ para essa variável, respectivamente. Entretanto, estes valores são inferiores àqueles obtidos por Wood e Ebanks ${ }^{18}$ que encontraram valores de $45 \%$, esses autores verificaram ainda, não haver diferença significativa entre sexos para valores desta variável, e que os mesmos parecem aumentar com a idade. Além disso, há que se ressaltar que fatores como dieta, saúde, exercício, hormônio circulante, temperatura e estresse podem afetar o VG de tartarugas mantidas em cativeiro. Destaque-se também que algumas doenças como infecções do plastrão, hemorragias prolongadas, deficiências nutricionais ou inanição, podem ser relacionadas à sua diminuição, atingindo nestes casos, valores abaixo de $20 \%{ }^{16}$.

A concentração de hemoglobina apresentou valor médio de $8,65 \mathrm{~g} / \mathrm{dl}( \pm$ $0,80)$, valor semelhante ao obtido por Aguirre et al. ${ }^{15} \mathrm{de} 8,54 \mathrm{~g} / \mathrm{dl}$, que trabalharam com a tartaruga verde. Mas, foi inferior ao encontrado por Wood e Ebanks ${ }^{5}$ de 10,6 $\mathrm{g} / \mathrm{dl}$ que também estudaram a espécie Chelonia mydas.

A média da contagem de eritrócitos encontrada neste trabalho foi de 275.000/ $\mu \mathrm{l}( \pm 28.030,59)$, sendo inferior aquela obtida

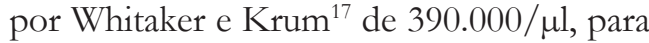
animais de cativeiro, o que talvez possa ser justificado pela pouca idade dos animais avaliados por estes autores. Este fato também foi obtido por Wood e Ebanks ${ }^{5}$ e Aguirre et $a .^{15}$ que citam valores de $341.000 / \mu \mathrm{le}$ $480.000 / \mu \mathrm{l}$ respectivamente, contudo a espécie em estudo foi a Chelonia mydas, possivelmente em condições alimentares de manejo diferentes as empregadas nesta pesquisa. Os cálculos dos índices hematimétricos Volume Globular Médio (VGM) e Hemoglobina Globular Média (HGM) mostraram discrepâncias ao serem comparados aos obtidos por Aguirre et al. ${ }^{15}$ para a Chelonia mydas. Valores de $725 \mathrm{fl}( \pm$ $131,99)$ e 198,18 pg ( \pm 38,66), foram obtidos neste trabalho, enquanto que aqueles obtiveram um VGM de 1.214,36 fl e HGM de 317,12 pg, respectivamente. Já, o valor da Concentração de Hemoglobina Globular Média (CHGM) de 26,10\% ( $\pm 1,21)$ foi bem próximo ao encontrado por esses autores, de $27,50 \%$.

O valor médio do número de

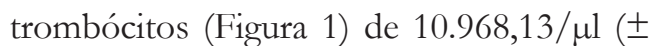
$3.109,19)$ foi bem parecido àquele obtido por Wood e Ebanks ${ }^{5}$ de $11.520 / \mu 1$, para tartaruga verde de cativeiro. Estes autores citam que a variável parece não ter correlação 
com idade ou sexo.

A contagem total de leucócitos, de $3.656 / \mu \mathrm{l}( \pm 963,04)$ se diferenciou da média observada na literatura consultada, onde Wood e Ebanks ${ }^{5}$ demonstraram valores de $32.000 / \mu \mathrm{l}$ e Aguirre et al. ${ }^{15}$ de $9.340 / \mu \mathrm{l}$, porém para a tartaruga verde. Outro ponto a ser lembrado é que a população em estudo neste trabalho é composta principalmente por fêmeas, que devido à presença de hormônios, como a gonodotrofina e esteróides sexuais, normalmente apresentam contagens inferiores às do macho ${ }^{5}$. A contagem diferencial de leucócitos, com os seguintes valores relativos: heterófilos (Figura 2) $59,37 \%( \pm 16,27)$, eosinófilos (Figura 3 ) $10,38 \%$ ( \pm 6,32), basófilos $0,13 \%$ ( $\pm 0,35)$, linfócitos (Figura 4) 29,25\% ( \pm 17,12), monócitos (Figura 5) 0,88\% ( $\pm 2,10$ ), mostrou-se em desacordo com a literatura citada, porém mesmo entre os autores citados há valores distintos, possivelmente devido à grande variação entre indivíduos da mesma faixa etária ${ }^{5}$, à dificuldade de classificação dos leucócitos, que possuem morfologia variável, entre os répteis em geral $^{9}$, além da difícil diferenciação entre linfócitos e trombócitos ${ }^{7,18}$.

A concentração da proteína plasmática total, com média de $6,5 \mathrm{~g} / \mathrm{dl}$
$( \pm 0,83)$ é relativamente alta quando comparada àquela obtida por Bolten et al. ${ }^{5}$, em trabalho realizado com a espécie Caretta caretta, e Aguirre et al. ${ }^{1}$, assim como para a espécie Chelonia mydas, de 4,1 e 4,32 g/dl, respectivamente. Essa diferença pode ter sido causada pelos métodos utilizados, já que os primeiros autores realizaram a técnica de análise colorimétrica automatizada, enquanto que neste trabalho foi a da refratometria.

\section{Conclusão}

De acordo com os resultados obtidos, conclui-se que dos parâmetros avaliados neste trabalho o volume globular, a concentração de hemoglobina, a concentração de hemoglobina globular média (CHGM) e o número de trombócitos, não divergiram de grande parte da literatura consultada. Enquanto que os valores da contagem de eritrócitos, volume globular médio (VGM) e hemoglobina globular média (HGM) foram inferiores aos obtidos pelos autores consultados. As contagens total e diferencial de leucócitos variaram bastante em relação a literatura consultada. A determinação da proteína plasmática total teve um valor superior àqueles citados pela literatura.

\section{Hematologic examination and total protein values of sea turtles of species Caretta caretta (Linnaeus, 1758), in captivity, from Praia do Forte, Mata de São João - Bahia}

\begin{abstract}
With the purpose in obtaining measurable parameters of hematologic examination and total protein test values of eight sea turtles of species Caretta caretta in captivity, $5 \mathrm{~mL}$ of blood were collected from dorsal cervical sinus using heparin as anticoagulant. The results showed average amounts of erythrocytes of $275.000 / \mu \mathrm{l}( \pm 28.030,59)$, packed cell volume of $33,12 \%( \pm 2,35)$, hemoglobin concentration of 8,65 $\mathrm{g} / \mathrm{dl}( \pm 0,80)$, while the erythrocytic indexes were $725 \mathrm{fl}( \pm 131,99)$ for mean corpuscular volume (MCV), 198,18 pg $( \pm 38,66)$ for mean corpuscular hemoglobin $(\mathrm{MCH})$ and $26,10 \%( \pm 1,21)$ for mean corpuscular hemoglobin concentration (MCHC). The leukocyte response showed an average of WBC counting of 3.656/ $\mathrm{ll}( \pm 963,04)$, and the average numbers relating to the leukocyte count were $59,38 \%$ $( \pm 16.27)$ for heterophils, $10,38 \%( \pm 6,32)$ for eosinophils, $0,13 \%$
\end{abstract}

\author{
Key-words: \\ Hematologic \\ examination. \\ Protein test values. \\ Sea turtle. \\ Caretta caretta.
}


$( \pm 0.35)$ for basophils, $29,25 \%( \pm 17,12)$ for lymphocytes and $0,88 \%$ $( \pm 2,10)$ for monocytes, being those absolute values of $2.156,87 / \mu \mathrm{l}$ $( \pm 703,49) ; 366,88 / \mu \mathrm{l}( \pm 216,44) ; 2,50 / \mu \mathrm{l}( \pm 7,07) ; 1.110,94 / \mu \mathrm{l}$ $( \pm 783,61)$ e $19,06 / \mu \mathrm{l}( \pm 42,34)$, respectively. The average amount of trombocytes found equaled $10.968,13 / \mu \mathrm{l}( \pm 3.109,19)$ and the total protein finding of an average $6,5 \mathrm{~g} / \mathrm{dl}( \pm 0,83)$. Of all variables analyzed, the erythrocytes count, the mean corpuscular volume, the mean corpuscular hemoglobin and all leukocyte counts presented different values for the relevant species when compared to published literature.

\section{Referências}

1 DIVERS, S. J.; REDMAYNE, G.; AVES, K. Haematological and biochemical of 10 green iguanas (Iguana iguana). The Veterinary Record, v. 138, n. 3, p. 203 - 205, 1996.

2 BOLTEN, A. B.; BJORNDAL, K. A. Blood profiles for a wild population of green turtles (Chelonia mydas) in the southern Bahamas: size-specific and sex-specific relationships. Journal of Wildlife Diseases, v. 28, n. 3, p. $407-413,1992$.

3 Sea turtle red blood cell parameters correlated with carapace lengths. Comparative Biochemistry and Physiology, v. 56A, n. 4, p. 467 - 472, 1977.

4 GOTTDENKER, N. L.; JACOBSON, E. R. Effect of venipuncture sites on hematological and clinical biochemical values in desert tortoises (Gopherus agassizii). American Journal of Veterinary Research, v. 56, n. 1, p. $19-21,1995$.

5 WOOD, F. E.; EBANKS, G. Blood cytology and hematology of the green sea turtle, Chelonia mydas. Herpetologica, v. 40, n. 3, p. $331-336,1984$

6 BOLTEN, A. B.; JACOBSON, E. R.; BJORNDAL, K. A. Effects of anticoagulant and autoanalyzer on blood biochemical values of loggerhead sea turtle (Caretta caretta). American Journal of Veterinary Research, v. 53, n. 12, p. 2224 - 2227, 1992.

7 WORK, T. M., et al. Morphologic and cytochemical characteristics of blood cells from Hawaiian green turtles. American Journal of Veterinary Research, v. 59, n. 10, p. 1252 - 1257, 1998.

8 OWENS, D. W.; RUIZ, G. J. New methods of obtaining blood and cerebrospinal fluid from marine turtles. Herpetologica, v. 36, n. 1, p. 17 - 20, 1980.

9 KNOTKAVA, Z.; et al. Blood cell morphology and plasma biochemistry in Russian tortoises (Agrionemys harsfieldi). Acta Veterinaria, v. 71, n. 2, p. 191 - 198, 2002.

10 PAGE, C. D.; MAUTINO, M. Clinical management of tortoise. Compendium on Continuing Education for the Practicing Veterinarian, v. 12, n. 2, p. 221 - 228, 1990.

12 NATT, M. P.; HERRICK, G. A. A new blood diluent for counting erythrocytes and leukocytes of the chicken. Poultry Science, v. 31, p. 735 - 738, 1952.

13 BIRGEL, E. H. et al. Patologia clínica veterinária. São Paulo: Sociedade Paulista de Medicina Veterinária, 1983, 260 p.

14 LUTZ, P. L.; DUNBAR-COOPER, A. Variations in the blood chemistry of the loggerhead sea turtle, Caretta caretta. Fishery Bulletin, v. 85, n. 1, p. $37-43,1987$.

11 JAIN, N. C. Schalm's veterinary hematology. 4 ed. Philadelphia: Lea \& Febiger, 1986. 1221 p.

15 AGUIRRE, A. A. et al. Adrenal and hematological responses to stress in juvenile green turtles, Chelonia mydas, with and without fibropapillomas. Phisiologycal Zoology, v. 68, n. 5, p. 831 - 854, 1995.

16 FRAIR, W. Turtles red blood cell packed volumes, sizes, and numbers. Herpetologica, v. 33, n. 2, p. 167 - 190, 1977.

17 WHITAKER, B. R.; KRUM, H. Medical management of sea turtles in aquaria. In: FOWLER, M. E.; MILLER, R. E. Zoo \& Wild animal medicine: v.4. Filadelfia: W. B. Saunders Company, 1999. p. 217 - 231.

18 ALLEMAN, A. R.; JACOBSON, E. R.; RASKIN, R. E. Morphologic and cytochemical characteristics of blood cells from desert tortoise (Gopherus agassizii). American Journal of Veterinary Research, v. 53, n. 9, p. 1645 $1651,1992$.

19 FRAIR, W.; SHAH, B. K. Sea turtle blood serum protein correlations with carapace lengths. Comparative Biochemistry and Physiology, v. 73A, n. 3, p. 337 339, 1982. 